\title{
A Virtual Reality Platform for Analyzing Remote Archaeological Sites
}

\author{
Brendan Cassidy, Gavin Sim \\ Department of Computing \\ University of Central Lancashire \\ Preston, UK. PR1 2HE \\ \{BCassidy1, GRSim\}@uclan.ac.uk
}

\author{
David Wayne Robinson \\ Department of Archaeology \\ University of Central Lancashire \\ Preston, UK. PR1, 2HE \\ DWRobinson@uclan.ac.uk
}

\author{
Devlin Gandy \\ Department of Archaeology \\ University of Cambridge \\ Cambridge, UK. CB2 3DZ \\ Dag52@cam.ac.uk
}

\begin{abstract}
This paper describes a virtual reality prototype developed to help archaeologists and other stakeholders explore and analyse archaeological data in a more immersive context. We describe a VR reconstruction of Pleito Cave, a fragile world class rock art site with accessibility limitation. Key stakeholders are identified and a prototype is described that provides a VR platform for visualising and interacting with complex archaeological data (gathered from techniques such as decorrelation stretch and $x$-ray fluorescence) virtually 'in situ', in a way that would not be possible at the real site. The prototype allows multiple remote users to interact with the cave together simultaneously providing opportunities for collaborative interpretation and analysis of archaeological data.
\end{abstract}

Virtual Reality. VR. Mixed Reality. Archaeology. Heritage. Data Visualisation.

\section{INTRODUCTION}

Archaeologists commonly use reality capture techniques such as Photogrammetry and laser scanning to capture, and keep a record of archaeological sites and the artefacts found in them (Barstanti, 2015). Since the release of Virtual Reality (VR) headsets at consumer level they have become an attractive tool for museums and heritage organisations to help engage the public with historic environments and artefacts found in them. With the release of lower cost standalone VR headsets, such as Oculus Go, they are also becoming more accessible to the general public at home. While the literature on designing for virtual museums is extensive, what is less clear is to what extent VR platforms can be used not only to engage the public, but also as a research communication tool for archaeologists wanting to visualize and interact with real-world archaeological data in an immersive way. This paper describes the initial development of a platform designed to allow key stakeholders to interact with archaeological data, in addition to 3D recreations of the site. Specifically, the work is focussed on providing a platform for multiple stakeholders with archaeologists, land owners, and people with a cultural connection to the sites being the main focus.

Often, important archaeological sites can be difficult to access, which restricts the stakeholder's ability to visit the site when they would like. This could be for a number of reasons: the fragility of the archaeological remains; existence on private property; the remoteness; difficulty of access; and dangers associated with natural phenomena (high cliffs, deep caves, underwater, etc.) or cultural reasons (areas of conflict, contamination, damaged buildings, etc.). Health issues such as restricted mobility, age or even transportation may equally affect the ability of individuals to experience archaeological sites. The introduction of immersive technologies into the archaeological and heritage sector presents an opportunity to overcome these access problems in new ways, and for multiple stakeholders.

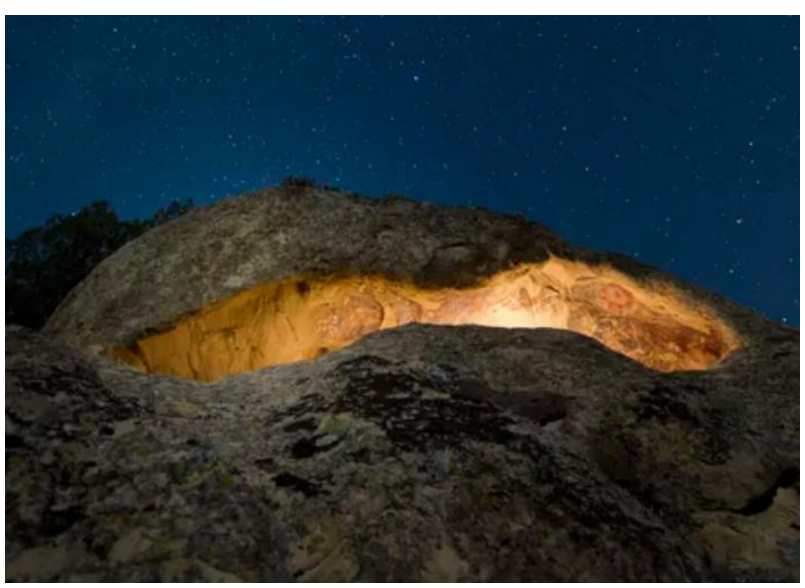

Figure 1: Pleito Cave site

The work presented in this paper describes an interactive re-creation of Pleito cave (Figure 1), one of the most elaborately painted rock-art sites in the world, located in the San Emigdio Mountains, California. The site has accessibility issues due to the fragile nature of the rock art found at the site and its remote geographical location. Recent work at the site has generated a lot of rich archaeological data (Robinson et al. 2015, Kotoula 
et al. 2018, Bedford et al, 2018) and makes it uniquely appropriate for prototyping immersive platforms to address issues of accessibility and archaeological data visualisation. The prototype addresses accessibility issues by supporting simultaneous multi-user access and initially supports data visualisation by overlaying digitally enhanced/processed textures of the rock art onto the original geometry, allowing users to walk around and interact with the processed textures in situ' to provide a viewing context previously unavailable to researchers. In effect, this is providing an 'Enhanced Reality' to allow archaeologists to view and interact with archaeological data not visible in a standard photo realistic reconstruction of the site.

\section{BACKGROUND AND RELATED WORK}

Designing virtual heritage spaces is a wellresearched area (Bekele et al, 2018). While the majority of virtual museum exhibits are solitary experiences for the user, $\mathrm{Li}$ and Zhou (2016) describe a multi-user virtual exhibit. The work describes a re-creation of an aircraft carrier using popular $3 \mathrm{~d}$ modelling tools. While there is novelty in facilitating a multi-user experience, the models used are not taken from real data, so would have limited value where high accuracy, realistic representations of the environment are required and would not be of practical use to researchers.

Research has also examined the impact of digital additions to artwork in a VR museum setting (Hurst et al, 2016). Hurst evaluated whether adding visual augmentations to a piece of art, or adding small 3D animations related to its content, had a positive impact on the experience and on how the art is perceived. The additions were still creative in nature and so are of limited use where scientific accuracy is required, but there is a suggestion from this work that manipulating artwork in a VR environment could lead to improved user experience. This view is also supported by Sim et al. (2018) who explored the enhancement of children's museum experiences through the design of augmented reality within the context of a Roman museum.

Where scientific accuracy is important photogrammetry is a popular technique used to digitise archaeological sites and is well suited to cave sites large enough to allow multiple images from a camera to be taken at many different angles. The subsequent 3D models generated are then accessible on a wide range of devices, for example, Chan et al (2013) used tablets to render a cave in a physical space. The reconstruction was realistic, so the captured data would be of use to researchers wishing to study the site further. However, with a requirement to use a tablet as the 'window' into the virtual world interactions with the world are less immersive, less natural, and is unsuitable for distributed multi user scenarios. The novelty of the work in this paper is that it combines much that has been covered in the related work described, and provides a multi-user platform that is suitable for a range of target users and uses. Also, importantly, it can also be used as a data visualisation tool for archaeologists.

\section{PROTOTYPE DESIGN}

A photogrammetrically generated mesh and texture of the cave site and rock art was produced as illustrated in Figure 2.

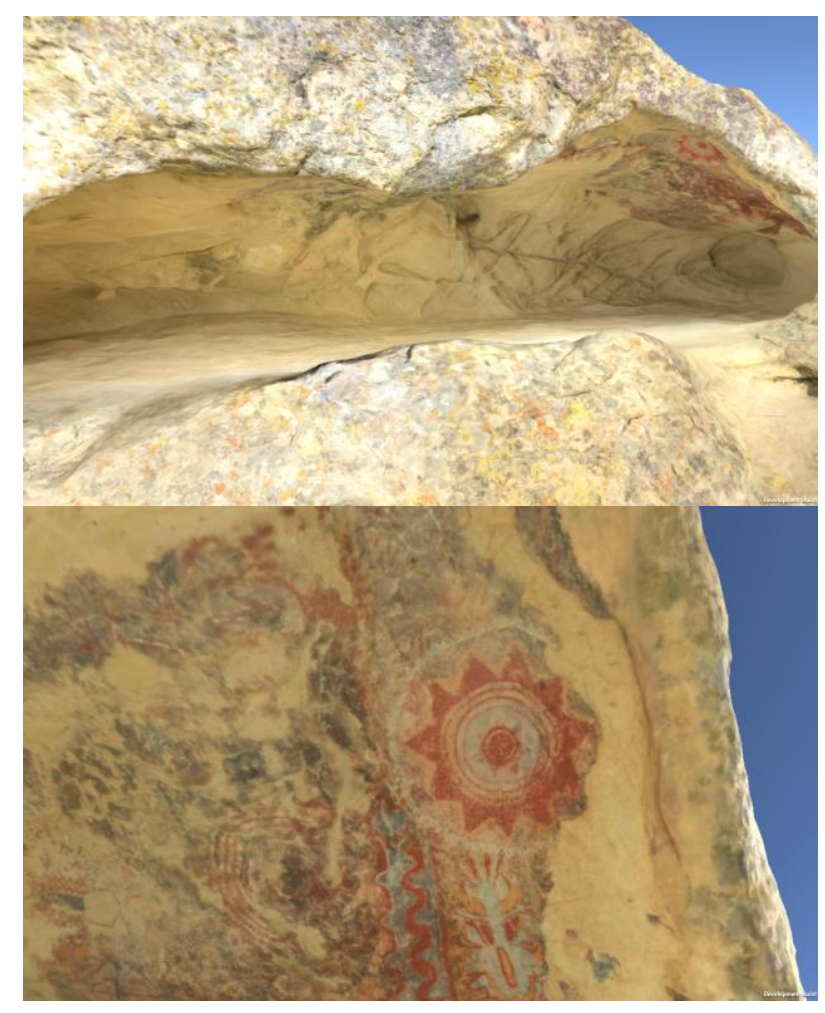

Figure 2: Virtual cave reconstruction and rock art detail

The photogrammetry model of Pleito was constructed from 896 images taken with a Nikon D810 and a Nikon AF-S FX 20mm f/1.8G lens, mounted on a Manfrotto tripod. The camera was set to raw (.nef), base ISO of 64 , and lens at f13. Photographs were taken at night, with the cave illuminated by five Switronix 250w TorchLED panels, each set to $4000 \mathrm{k}$. Due to complex cave features, limitations of lighting placement, and brightness of LED panels, exposure varied from 215 ", which allowed us to manually light paint sections of the cave if needed. We used a X-Rite Color Checker ${ }^{\mathrm{TM}}$ incrementally throughout the session to confirm light temperature and serve as a color correction base for post-processing. Our photogrammetry image capture protocol emphasized a $>66 \%$ overlap between images and 
followed best practice for complex objects as outlined by Cultural Heritage Imaging (2017). Measurements of 20 distinctly identifiable cave features as well as eight $10 \mathrm{~cm}$ scales served to scale the model. Images were processed in Photoshop CC (version 18.0) and exported as JPEGs. The photogrammetry model was modelled in Agisoft PhotoScanPro (Version 1.3.0 build 3075)

The model was then optimised for VR in MeshLab and imported into the Unity 3D Game engine. The Virtual Reality Toolkit software library (Ball, 2018) was used to integrate locomotion and interactivity in VR. The target device was Oculus Rift and the Oculus Avatar SDK and Oculus Touch controllers were used to provide hand presence. The Avatar SDK provides a Unity plugin supporting social features to allow co-location. This integrates directly with the Oculus platform and allows any user who is connected as a friend on the oculus platform, and has the prototype application installed to join them in the cave.

\subsection{Key User Groups}

The key stakeholders targeted with this prototype include site owners/managers, archaeologists and people who culturally identify with the site. Each user group has different needs and will want to interact with the site in a different way.

\subsubsection{The Tejon Indian Tribe of California}

The Tejon Indian tribe, a recently federally reinstated pluralistic tribe, are the key stakeholders who identify with the proposed archaeological sites. The paintings found on the walls of the cave were created by hands of their ancestors. An early prototype was tested with the Tejon and other Native people to trial the immersive environment. The response was positive, with Native children responding particularly well to the virtual environment. Equally, the prototype proved effective for use by elders who had mobility issues who could not access and navigate the site themselves. With further work, we aim to provide a platform to re-connect tribal members to sites and practices no longer in living memory.

\subsubsection{The Wind Wolves Preserve}

The Wind Wolves preserve are the key stakeholders who own the land where the archaeological sites are located. The Preserve's objective is to conserve the environment and the over 150 known archaeological sites on their property, while promoting public education. The platform is being used with visitors at their visitor centre as well as for other events. Importantly, it will be a component of their children/young people's education and outreach programs that form a core aspect of their mission. Furthermore, Since the prototype is designed to provide access to sites not normally accessible, it is an important site management tool to deflect potential harmful visitation, thus promoting cultural resources without damaging them.

\subsubsection{Archaeologists}

Perhaps one of the most striking aspects of the interactive platform developed is the ability to augment real archaeological data 'in situ' onto the virtual cave walls retaining a location dependant context that is lost during the initial archaeological data collection process. This enhanced method of data visualisation has promising implications for exploring, interpreting and analysing archaeological data. The remote-user support also allows collaborators and experts from around the world to immerse themselves in the prototype to bring their own expertise to exploring and interpreting the data presented.

\section{CO-LOCATION}

One of the difficulties with inaccessible, fragile archaeological sites is that it is often difficult for key stakeholders to visit a site together. This could be because they are unable to physically get to the location of the site, or because the site itself will not support a large number of simultaneous visitors. The platform supports virtual co-location of users through use of the Oculus Avatar SDK. Figure 3 illustrates two users co-located in the cave.

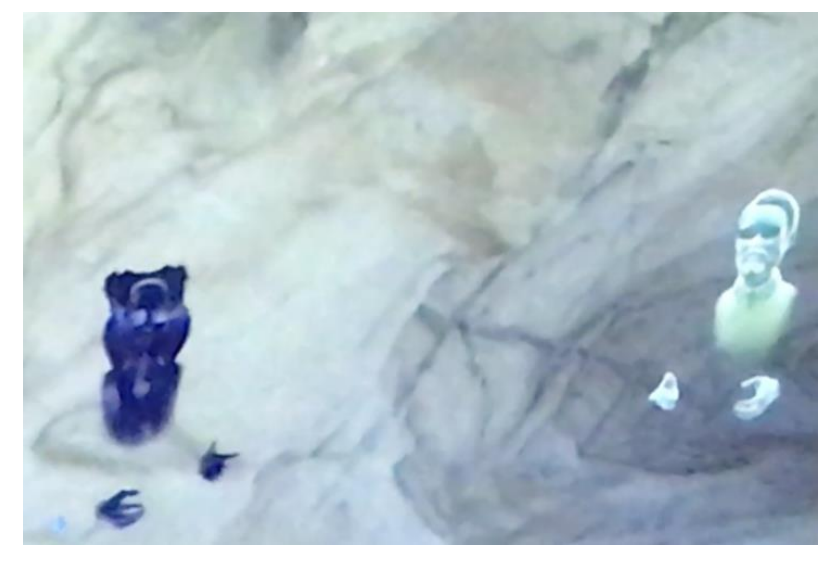

Figure 3: Co-Location with the Avatar SDK

Full voice, hand and head presence is supported for up to four people. allowing users to move around, discuss and point out areas of interest to each other within the cave. A remote trial of the platform was tested with domain experts at the 2018 Society for American Archaeology (Cassidy et al, 2018). In the trial, representatives from the three main stakeholder groups (The Wind Wolves Preserve, Tejon Indian Tribe \& Archaeologists) along with the developers of the interactive platform successfully gave an informal demonstration from within the cave while simultaneously located in Washington DC, California and the UK. 


\section{ENHANCED REALITY}

When analysing rock art, archaeologists often photograph the areas of interest and use image processing techniques such as Decorrelation Stretch (Harman, 2006) on the image to reveal or enhance detail that is difficult to see with the naked eye. By applying this technique to the photogrammetry models high resolution textures archaeologists are able to immerse themselves within and interact with the cave in a way they would not be able to do at the real site.

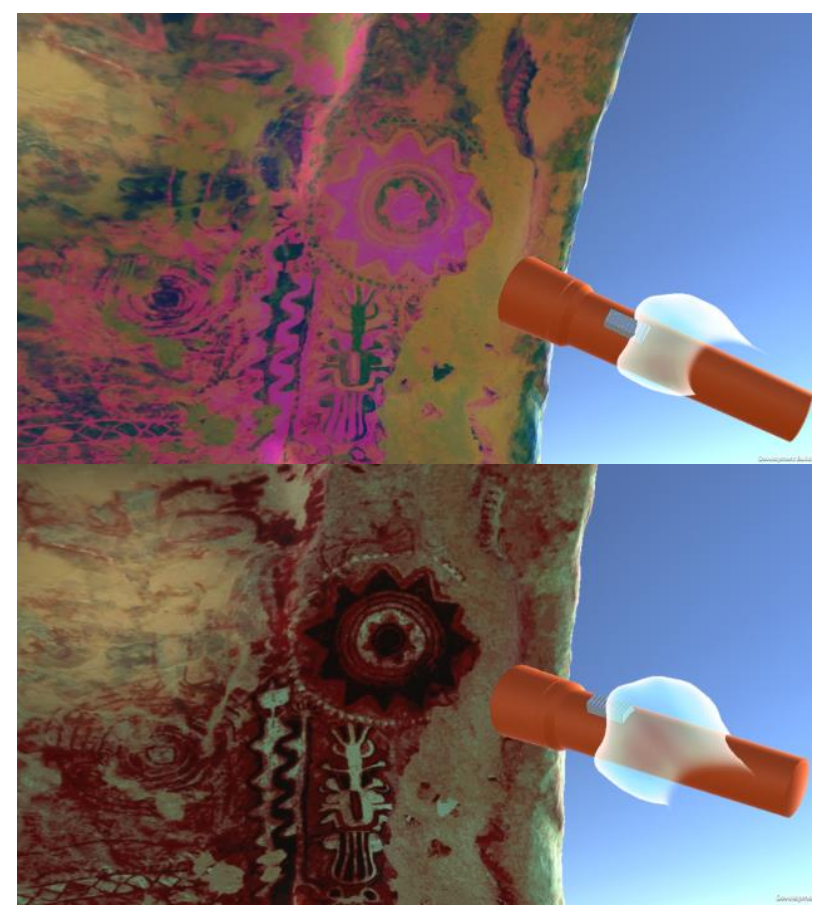

Figure 4: Immersive visualisation of fugitive elements

Figure 4 illustrates a 'Flashlight' tool within the cave that allow users to naturally explore the rock art, switching between normal and processed textures in a way that feels natural. If the user notices any unusual elements when browsing the processed textures, they are able to shine the flashlight tool to reveal the original rock art beneath. We aim to extend this type of data visualisation to support other sources of data such as paint pigment analysis.

\section{FURTHER WORK}

Using a technique known as 'Portable X-ray Fluorescence' combined with advanced imaging processes it is possible to analyse the various layers of overpainting that have occurred in the cave over the years. Using data already gathered from the site (Bedford et al, 2016; 2018; Gandy and Robinson 2018; Kotoula et al. 2018), we are able to reconstruct not only what the cave looks like now as a static record, but also visualise how the cave would have looked over time, by starting with a virtual 'blank canvas' we are able to separate the layers of overpainting providing an immersive 'walk in' visualisation of how the paint was built up over time. This unique perspective is not possible to achieve when interacting with the real site and is the next immediate focus of the work, followed by user studies aimed at identifying how stakeholders interpret the data when presented in different ways.

\section{ACKNOWLEDGEMENTS}

The authors wish to thank the Tejon Tribe, including Mark Sanchez, Sandra Hernandez and Colin Rambo for their involvement and support of this research. We also thank the Board of The Wildlands Conservancy and the staff of Wind Wolves Preserve, for their permission and support for this work. Thanks to Julie Bernard, Gloria Brown, Joshua Roth, Colin Rosemont, Allison Hill, and the entire field work team. Funding for this project was provided by the University of Central Lancashire and the Arts and Humanities Research Council (AHRC) 'Unravelling the Gordian Knot: Integrating Advanced Portable Technologies into the Analysis of Rock-Art Superimposition' (Project reference AH/M008894/1). Thanks to project team members Jenn Perry, Matthew Baker, Eleni Kotoula, Rick Bury, and Antoinette Padget.

\section{REFERENCES}

Ball, H., 2018, The Virtual Reality Toolkit https://vrtoolkit.readme.io/ (retrieved 15/05/2018)

Barsanti, S.G., Caruso, G., Micoli, L.L., Rodriguez, M.C. and Guidi, G., 2015. 3D visualization of cultural heritage artefacts with virtual reality devices. The International Archives of Photogrammetry, Remote Sensing and Spatial Information Sciences, 40(5), p.165.

Bedford, C., Gandy, D. \& Robinson, DW. 2018. Emigdiano Blues: the California indigenous pigment palette and an in situ analysis of an exotic colour. Journal of Open Archaeology 4:152-172.

Bedford, C., Robinson, D., Perry, J., Baker, M., Miles, J., Kotoula, E., Gandy, D., \& Bernard, J., 2016. Unravelling the Gordian Knot: Combining Technologies to Analyse Rock Art in Pleito Cave, Society for California Archaeology Proceedings 30:183-195.

Bekele, M.K., Pierdicca, R. Frontoni, E. Malinverni, E.S \& Gain, J. 2018. A Survey of Augmented, Virtual, and Mixed Reality for Cultural Heritage. J. Comput. Cult. Herit. 11, 2, Article 7 (March 2018), 36 pages.

Cassidy, B, Robinson, D \& Gandy. D., 2018. Accessing the inaccessible: Valuing Virtual Reality and remote access to Pleito Cave. 
Presentation at the Society for American Archaeology Association 83rd Annual Meeting, Washington D.C.

Gandy, D., \& Robinson, D., 2018. The Gordian Knot: Novel Methods for Digitally Identifying, Defining, and Separating Unique Rock Art Elements. Presentation at the Society for American Archaeology Association 83rd Annual Meeting, Washington D.C.

Harman, J., 2006, A tool for the digital enhancement of pictographs http://www.dstretch.com/ (retrieved 15/05/2018)

Hürst, W., De Coninck, F., \& Tan. XJ. 2016. Complementing Artworks to Create Immersive VR Museum Experiences. In Proceedings of the 13th International Conference on Advances in Computer Entertainment Technology (ACE '16). ACM, New York, NY, USA, Article 34, 6 pages.

Kotoula, E., Robinson, DW \& Bedford, C. 2018. Interactive Relighting, Digital Enhancement and Inclusive Diagrammatic Representations for the Analysis of Rock Art Superimposition: the Main Pleito Cave (CA, USA). Journal of Archaeological Science 93:26-41.

Li, L. \& Zhou, J. 2016. Virtual reality technology based developmental designs of multiplayer- interaction-supporting exhibits of science museums: taking the exhibit of "virtual experience on an aircraft carrier" in China science and technology museum as an example. In Proceedings of the 15th ACM SIGGRAPH Conference on Virtual-Reality Continuum and Its Applications in Industry - Volume 1 (VRCAl '16), Vol. 1. ACM, New York, NY, USA, 409-412.

Robinson, DW., Baker, MJ,. Bedford, C,. Perry, J., Wienhold, M., Bernard, J,. Reeves, D,. Kotoula, E,. Gandy, D., \& Miles. J., 2015. Methodological Considerations of Integrating Portable Digital Technologies in the Analysis and Management of Complex Superimposed Californian Pictographs: from Spectroscopy and Spectral Imaging to 3- D scanning. Digital Applications in Archaeology and Cultural Heritage 2(2-3): 166-180

Sim, G., Cassidy, B. and Read, J.C., 2018. Crowdsourcing Ideas for Augmented Reality Museum Experiences with Children. In Museum Experience Design (pp. 75-93). Springer, Cham.

Yip Chan, LK,. Kenderdine, S., \& Shaw., J. 2013. Spatial user interface for experiencing Mogao caves. In Proceedings of the 1st symposium on Spatial user interaction (SUI '13). ACM, New York, NY, USA, 21-24. 